\title{
Government Activity to Increase Benefits from the Global Standards System
}

\author{
By:
}

R.B. Marks

R.E. Hebner

2nd IEEE Conference on Standardization and Innovation in Information Technology, Boulder, CO, October 3-6, 2001

2nd IEEE Conference on Standardization and Innovation in Information Technology, pp 183-190.

$$
\text { PR }-316
$$

Center for Electromechanics

The University of Texas at Austin

PRC, Mail Code R7000

Austin, TX 78712

(512) 471-4496 


\title{
GOVERNMENT ACTIVITY TO INCREASE BENEFITS FROM THE GLOBAL STANDARDS SYSTEM*
}

\author{
Roger B. Marks \\ NATIONAL InSTITUTE OF STANDARDS AND TECHNOLOGY \\ Robert E. Hebner \\ THE UNIVERSITY OF TEXAS AT AUstiN
}

In this paper, we review the factors influencing the evolution of the global standards system. We then discuss some of the approaches that governments have taken or are exploring in order to modify the system for the benefit of domestic and worldwide economic development. We use as an example an effort of the U.S. National Institute of Standards and Technology to encourage voluntary consensus standards for interoperable broadband wireless access systems.

$\mathrm{G}$ lobalization of the economy has in turn led to globalization of standardization. Governments play a strong role in shaping the global standards system. They have explored many approaches to optimize the system to meet their economic and social needs. Governmental activity sometimes conflicts with the interests of other governments or of local industry. In this paper, we investigate some of these issues.

\section{Benefits of Standards}

The benefits of standards in a modern economy have been classified into four categories [1]:

- Quality and reliability - Standards may define an acceptable level of performance. The standards dealing with boilers and pressure vessels that have been promulgated by the American Society of Mechanical Engineers are good examples. Governmental regulators have sometimes made these standards legally binding to assure a minimum level of public safety.

- Information - Standards may provide evaluated scientific and technical information. For example, in the construction industry; the latest research, from concrete handling to earthquake protection, is evaluated and incorporated into standards. The construction crews and engineers who use these standards can thereby exploit advanced technical information without independent knowledge of all recent research.

- Compatibility and interoperability - Standards may provide agreed-upon interfaces so that systems can operate with parts from different manufacturers. Examples are commonplace and include nuts and bolts, railroad gauges, electrical plus and outlets, and interoperability standards for computer and telecommunication systems.

- Variety reduction - Standards may limit the number of possible variants of a product or process. Such reductions lead to economies of scale and can also stimulate economic growth. Standardizing the size of a bread slice led not only to an economy of scale for commercial bakers but also to inexpensive toasters and plastic sandwich bags.

As a result of benefits like these, standards have proliferated. About 200,000 exist [2], with broad implications in industry and society.

\section{Key Factors Forcing Changes in Standards Development}

Two key interrelated factors are stimulating changes in the system by which standards are developed and promulgated. The first is the end of the Cold War. During the Cold War, the world was divided into two adversarial

\footnotetext{
*U.S. Government work, not subject to U.S. Copyright.
} 
camps, plus a group of nonaligned nations. In this environment, global trade was constrained and standards tended to be largely national, or harmonized among allied trading partners when convenient. With the end of the Cold War, a truly global economy began to emerge. With increasing mobility of capital, investment flowed to countries with low inflation, a nearly balanced budget, a strong private sector, deregulated trade and investment, and economic competition [3]. In this environment, the existing system of differentiated standards emerged as a key barrier to trade.

The second factor is the increasing rate at which new technologies are introduced into the economy. During the 1980s, many companies demonstrated the economic benefits of aggressively bringing new technology to market. This fact, paired with exponential improvements in microelectronic technology, dramatically shortened some product life cycles to periods measured in months. Short product life cycles create problems for the standards process [4]. Standards are reached by consensus, and development times of five years have been common for complex standards. Inefficiencies in development and information transfer cause some of this delay. These issues are being addressed by many standards-developing organizations through increased use of automation and streamlined procedures. However, some factors behind the delays are less responsive to a technical fix. The development of a consensus standard requires people to agree. Different participants in the process have different expectations and concerns to be identified and resolved. All participants recognize, however, that a standard whose development time exceeds the life of the product is of little use.

\section{Industrial Response to Global Changes}

As the geopolitical barriers to global trade were removed, industry moved to compete in and profit from a global market. This trend had implications in the standards arena. For example, in 1995, the Transatlantic Business Dialogue was established "to reduce barriers to transatlantic trade and investment" [5]. This organization brought together leaders of companies with headquarters in Europe and the United States to work closely with government officials in finding creative means to remove trade barriers. In the area of standards, a guiding principle became, "approved once, accepted everywhere."

Industry also modified its own standards-developing organizations. For example, the American National Standards Institute (ANSI) developed and disseminated the "National Standards Strategy for the United States" [6]. This document culminated an industry-led process to clearly define which elements of the existing standards system needed to change and which needed to be preserved.

Industry was also taking direct action to bypass the traditional standards process that leads to de jure [7] standards. Such changes were driven partially by a perception that the accredited standards process was too slow and partially by a perception that an aggressive approach could lead to huge returns. This attitude was captured in Wired magazine's "encyclopedia of the new economy" [8] that asserted:

"Companies used to compete by making things and selling them. In the new economy, the game is often over by the time the first product emerges from the factory. Sometimes it's because a... first entrant effectively sets... the standard. In other cases, winners (and losers) emerge from backroom bargaining over the technical details that enable complex technologies to work together..."

Geoffrey Moore [9] identifies Microsoft, Intel, and Cisco Systems as companies that have benefited by de facto standards.

Economists have recently focussed on network externalities and "lock-in" effects that result from or de jure or de facto standards. Such economic network effects are exemplified in hardware that, once widely deployed, offers a ready market to software developers and stimulates further hardware sales. Telecommunications networks also provide excellent illustrations of such effects. Examples of exceptional success based on lock-in have become widely known. As these economic models have become better understood, strategies for their exploitation have become increasingly popular. Varian and Shapiro have published a book on the topic, advising [10]:

"A go-it-alone strategy typically involves competition to become the standard. By contrast, participation in a formal standards-setting process, or assembling allies to promote a particular vision of technology, typically involves competition within a standard. Don't plan to play the higher-stakes, winner-take-all battle to become the standard unless you can be aggressive in timing, in pricing, and in exploiting 
relationships with complementary products. Rivalry to achieve cost leadership by scale economics and experience, a tried and true strategy in various manufacturing contexts, is tame in comparison."

An important strategy in the lock-in game is to price aggressively to win early market share in the hope that profit will follow later, once customers find it expensive to change. This approach may require large capital investment and years of losses. Whether the capital markets will remain as kind to this strategy as they were in the 1990s remains to be seen.

Industry's approach to standards has been driven not only by economic change but also by the regulatory environment. For example, consortia specifications flourished in the 1990s. In the U.S., approximately 3500 consortia organizations develop specifications, compared to approximately 250 accredited standards-developing organizations [2]. Cooperative research and development consortia were given great antitrust leeway in the U.S. under the National Cooperative Research Act of 1984 (amended as the National Cooperative Research and Production Act of 1993 [11]). Under the Act, certain types of activities ("such as, arguably, the development of standards" [7]) are protected from the risk of treble damages and liability for a plaintiff's legal fees.

\section{Technical Barriers to Trade Agreement (TBTA)}

Given the economic benefit of standards, most countries want to assure that the standards process does not harm their industry and, if possible, boosts it. An important early step to adapt the world's standards system to global trade was the Technical Barriers to Trade Agreement (TBTA) [12], concluded during the 1994 Uruguay round of multilateral trade negotiations under the auspices of the World Trade Organization (WTO). A specific motivation for that agreement was to "encourage the development of... international standards... systems." Sections 2.4 and 2.6 impact government relationships with standards organizations. In Section 2.4, signatories agreed to use international standards as the basis for regulations whenever possible. As detailed in Section 2.6, the WTO signatories have also agreed to become participants in the preparation of international standards by "appropriate international standardizing bodies." This last term was undefined. Many organizations have defensible claims to be appropriate international standardizing bodies for various industries, technologies, or classes of products or processes.

As a result of Sections 2.4 and 2.6 of the TBTA, national regulations may now be determined partially by industry and, because of Section 2.6, partially by outside governments. This is consistent with the trend [3] of decreasing local autonomy in the global economy.

\section{U.S. Response to TBTA}

The U.S. standards system has its roots in private industry. Over the last century, it has successfully met marketplace needs on a sector-by-sector basis. It also has developed rules for consensus, transparency, openness, and due process, all of which have been adopted by the World Trade Organization as bedrock principles for developing sound and fair standards [2].

Many of the principles of the TBTA were echoed in the 1995 National Technology Transfer Advancement Act (NTTAA) [13]. The NTTAA has three major implications for the relationship between the government and standardization: (1) government procurement, (2) government regulations, and (3) government participation in standards development.

The NTTAA requires that, in general, "Federal agencies and departments shall use technical standards that are developed or adopted by voluntary consensus standards bodies, using such technical standards as a means to carry out policy objectives or activities determined by the agencies or departments." Unless the use of a privatesector standard is "inconsistent with applicable law or otherwise impractical," its use in specifying procurement criteria for a given purchase is mandatory [14]. In parallel with Section 2.4 of the TBTA, the NTTAA also applies to government agencies in their regulatory activities; wherever possible, Federal regulations are to be consistent with voluntary consensus standards.

In parallel with Section 2.6 of the TBTA, the NTTAA also requires that Federal agencies "shall, when such participation is in the public interest and is compatible with agency and departmental missions, authorities, priorities, and budget resources, participate with such bodies in the development of technical standards." This clause 
provides a route for direct government involvement in private standardization through voluntary consensusstandards bodies. We discuss this issue in greater detail below.

In 1998, the Executive Office of the President issued Office of Management and Budget (OMB) Circular A-119 [15], which implements the NTTAA with specific policy and language. Circular A-119 specifies that each federal agency "must use voluntary consensus standards, both domestic and international, in its regulatory and procurement activities in lieu of government-unique standards, unless use of such standards would be inconsistent with applicable law or otherwise impractical." A-119 then interprets "voluntary consensus standards" using language far more specific that that of the NTTAA and generally in accord with ANSI accreditation rules [16]. This definition excludes many consortia-developed standards, a fact that has been criticized before the U.S. House of Representatives [17]. Circular A-119 has had specific regulatory implications. For example, a number of comments filed before the U.S. Federal Communications Commission (FCC) have referred to Circular A-119, and the agency has, in at least one case, taken note of the accordance of its decision with A-119 [18].

So, following the TBTA, U.S. law has moved toward a domestic position parallel to that defined by the TBTA. One significant difference is that, while the TBTA puts "appropriate international standardizing bodies" in a key position, the U.S. has "voluntary consensus standards," sometimes defined according to ANSI accreditation policies, in a parallel position. Since "international standardizing bodies" are generally driven to a large degree by national interests while "voluntary consensus standards" are more representative of private interests, this distinct approach is in accord with the U.S. tradition of private-sector standardization.

\section{European Response to TBTA}

Compared to the U.S., Europe's standardization tradition involves a greater degree of government involvement. Furthermore, Europe has been integrating its economic activities in the 1990s. Perhaps as a result of these factors, the European response to the Technical Barriers to Trade Agreement has revolved around coordination of efforts regarding the more formal "international standardizing bodies." One noteworthy effort, consistent with the intent of the TBTA, was the effective development of the European Committee for Standardization (CEN) and the European Committee for Electrotechnical Standardization (CENELEC) within Europe. Both of these organizations, which trace their roots to the 1960 s or earlier, attempt to harmonize standards throughout Europe. With the development of open trade within the European Union, this harmonization became crucial to eliminate arbitrary standards-related trade barriers. The importance is underscored by the fact that about $40 \%$ of CEN's budget is covered by the European Union [19]. CEN and CENELEC are transnational, but not international, standards organizations. As such, they have made agreements that, if managed properly, can be used to assist industry within the European Union. The Vienna Agreement [20] and the Dresden Agreement [21] provided a mechanism for European harmonization to proceed nearly concurrently with international harmonization through the International Organization for Standardization (ISO) and the International Electrotechnical Commission (IEC). Both the IEC and the ISO are nongovernmental standards-developing organizations, with headquarters in Switzerland, that aspire to be truly global in their influence.

The ISO and the IEC each assign one vote to a country, typically cast by a private-sector national committee. This one-country/one-vote approach gives particular strength to well coordinated alliances. Funding, such as that provided by the European Union to CEN and CENELEC, can support such alliances. If the funding and the shared vision is sufficient, such an organization has the potential of influencing the agenda of the ISO or IEC and of accelerating or slowing the process for the benefit of the alliance. If, for example, companies operating within the alliance are not generally at the leading edge of technology, the alliance may seek to slow the standards process and adopt standards that impede the introduction of the latest technology. Conversely, an alliance of hightechnology countries could assist domestic companies to increase their market share by accelerating the standards process and thereby speed the introduction of new technology. So, the current ISO and IEC rules offer potential benefit in alliances.

\section{The U.S. National Standards Strategy}

Partially in reaction to European initiatives, many in the U.S. have called for a more coherent approach to standardization. ANSI's recently-unveiled U.S. National Standards Strategy [6] articulates these concerns: 
"The European Union is aggressively and successfully promoting its technology and practices to other nations around the world through its own standards processes and through its national representation in the international standards activities... Emerging economies with the potential for explosive growth are looking to ISO and IEC for standards. In some sectors these standards do not reflect U.S. needs or practices... The exclusion of technology supporting U.S. needs from international standards can be a significant detriment to U.S. competitiveness. The U.S. will lose market share as competitors work hard to shape standards to support their own technologies and methods. Equally important, standards are the basis for protection of health, safety and the environment. When our standards in these areas are not accepted elsewhere, we all lose."

U.S. governmental policy has evolved along the lines of these industry concerns. For example, in the "Memorandum of Understanding between the ANSI and the [U.S.] National Institute of Standards and Technology (NIST)" [16], the two organizations "agree on the need for a unified national approach to develop the best possible national and international standards, as reflected by the U.S. National Standards Strategy adopted by ANSI."

One important implication of the cooperation between ANSI and the U.S. government regards the definition of "voluntary consensus standards" and therefore the legal position of traditionally developed standards as compared to consortia-promoted specifications. The NIST-endorsed ANSI National Standards Strategy states that "U.S. interests strongly agree on the principles necessary for the development of national or international standards to meet societal and market needs." Among these principles of "successful standards processes" are consensus, open participation, balance, transparency, and due process. While the Strategy applauds the benefits of consortia-based specification development, it encourages coordination among consortia and traditional standards developers. It also requests the U.S. government to "encourage more use of the principles embodied in accreditation by recognizing the ANSI process as providing sufficient evidence that American National Standards (ANSI) meet federal criteria for voluntary consensus standards." These federal criteria may trace back to the definitions of voluntary consensus standards in the NTTAA and in OMB Circular A-119. Because of the intricate relationships among NIST, ANSI, consensus standards-developing organizations, and market-driven consortia, the details of the NTTAA and A-119 directly affect regulatory matters [22].

\section{U.S. Governmental Role in Standards Development}

According to Circular A-119, federal agencies "must consult with voluntary consensus standards bodies, both domestic and international, and must participate with such bodies in the development of voluntary consensus standards when consultation and participation is in the public interest and is compatible with their missions, authorities, priorities, and budget resources" (emphasis added). Agencies are authorized to contribute funds as well as personnel. Furthermore, "Agency representatives serving as members of voluntary consensus standards bodies should participate actively and on an equal basis with other members, consistent with the procedures of those bodies, particularly in matters such as establishing priorities, developing procedures for preparing, reviewing, and approving standards, and developing or adopting new standards. Active participation includes full involvement in discussions and technical debates, registering of opinions and, if selected, serving as chairpersons or in other official capacities. Agency representatives may vote, in accordance with the procedures of the voluntary consensus standards body, at each stage of the standards development process unless prohibited from doing so by law or their agencies."

Many voluntary consensus standards have relevance to one or more federal agencies, typically due to an agency's procurement requirements or regulatory authority. Circular A-119 is an imperative for those agencies to participate in standards development. However, one agency has a unique mission related to standards. The mission of the National Institute of Standards and Technology is "to strengthen the U.S. economy and improve the quality of life by working with industry to develop and apply technology, measurements, and standards." NIST lacks regulatory authority, and its procurement needs are rather small. However, the law seems to require NIST to participate directly in the development of voluntary consensus standards if such standardization will improve the economy and quality of life.

\section{An Example of Proactive NIST Action in Standards Development}

Standardization is a key driver in telecommunications. Since 1994, the U.S. position regarding wireless communications has been to auction spectrum and leave its use to successful bidders. Following years of regulated 
specifications, the wireless communications industry was slow to develop the traditions of consensus standardization. In the 1990s, Europe's broadly supported GSM standard developed a strong position in the world market for "second-generation" cellular telephones, while the U.S. market remained fractured. The standards wars of "third-generation" cellular were fought by many companies and consortia and ultimately in the International Telecommunications Union (ITU). As a treaty organization, the ITU voting policy is one country, one vote.

In 1998, NIST began looking at a different wireless application: fixed broadband wireless access providing high-speed network access to businesses, homes, and other stationary sites, generally through rooftop antennas [23]. NIST found little evidence of U.S. or worldwide efforts to standardize such services, although an early program in the European Telecommunications Standards Institute (ETSI) had begun. This application seemed ripe for standards [24], but industry needed a catalyst. NIST assumed the role and called a meeting to discuss the topic in August 1998. With the participation of 45 attendees, a plan was crafted to initiate the standardization process.

The plan developed by this group did not follow the traditional telecommunications model of creating one or more national standards and then moving toward an international standards competition. Instead, the plan was to follow the traditions established in data communications that had led to the global standards underlying the Internet. These standards had yielded a vibrant business in which customers were delighted with dramatically declining prices while manufacturers enjoyed ever greater sales. Following that model, the NIST-initiated group, after considering possible consortium development, elected to proceed with standardization through the ANSI-accredited Institute of Electrical and Electronics Engineers, Inc. (IEEE), a transnational nonprofit technical society of over 350,000 members [25]. In particular, that group approached the IEEE 802 LAN/MAN (Local/Metropolitan Area Networks) Standards Committee. IEEE 802 is the source of the ubiquitous Ethernet standards that define local area networks and have rapidly turned new technology into readily available commodity equipment. IEEE 802 has also become extremely active in wireless data networking, with an active and successful project in the IEEE 802.11 Wireless LAN standards and a more recent effort developing the IEEE 802.15 Wireless Personal Area Network standards [26].

In two months, the NIST-pioneered effort to create standards for fixed broadband wireless access led to an IEEE 802 Study Group chartered to develop a standardization plan. Four months later, this plan was approved, and the IEEE 802.16 Working Group on Broadband Wireless Access [27] was created and chartered to develop its first standards project. The group has grown to 161 Members (102 from the U.S.) and hundreds of active participants. Its web site received over 2.8 million file requests in 2000 . Holding bimonthly weeklong sessions, the group quickly developed draft specifications and is moving toward publication, in 2001, of the first two in its family of WirelessMAN ${ }^{\text {TM }}$ standards. Two other standards, for different frequency allocations, will follow, and all will make use of the same basic networking protocols.

In accordance with OMB Circular A-119, NIST has actively participated in IEEE 802.16 activities. After initiating the project, a NIST staff member (the first author of this paper) was elected 802.16 Chair; in accordance with IEEE 802 procedures, the Chair makes procedural decisions while the Working Group makes technical decisions. The same staff member serves as Chair and Technical Editor of the base standard (IEEE 802.16) and served as Technical Editor of the group's approved Recommended Practice (IEEE 802.16.2). He has organized a number of sessions and provided other services to maintain the group's momentum.

This activity fulfills NIST's mission in several ways:

- By encouraging standardization through the voluntary consensus standards process, the work supports the goals of the NTTAA, OMB Circular A-119, and the NIST-endorsed ANSI National Standards Strategy.

- By encouraging the development of standards in an open, global, technically based, consensus process, the project ensures that all participants, large and small alike and regardless of nationality, are given access to the process so that the resultant outputs are likely to be of high quality.

- By accelerating standardization, the work moves broadband wireless access closer to widespread deployment. This will expand opportunities for equipment vendors and service providers.

- By leading to wider deployment, standardization will offer more broadband access alternatives to a wider range of U.S. consumers and businesses, including those in locations that may otherwise be poorly served by more conventional broadband access networks. 
- By enhancing the deployment of broadband services, the work will expand the applicability of the Internet and its positive effect on the economy.

- By developing standards with global participation, the project will increase the chances of a uniform global result with broad export market opportunities for manufacturers in all countries.

NIST has also contributed its unbiased technical expertise to IEEE 802 standardization projects. In support of further such contributions, NIST has also planned to develop the National Wireless Electronic Systems Testbed (N-WEST) for use in measurements that contribute to effective standardization and compliance testing [28, 29]. Such an undertaking will require significant investment.

\section{Conclusions}

The world standards system has undergone rapid change and restructuring. The role of governments in the emerging system is beginning to take shape. Widely different models for government engagement exist in different regions of the world. Europe is primarily oriented toward interaction with formal international standardization bodies. In the United States, government and industry are agreeing that government should play an active role in encouraging and accelerating voluntary consensus standardization. NIST is demonstrating, through its participation in the IEEE 802.16 Working Group on Broadband Wireless Access, that this role can constructively contribute to the economy and quality of life.

[1] G. Tassey, The Economics of R\&D Policy, Quorum Books, Westport, CT. USA, 1997.

[2] Robert Hebner, "Standards and Trade - Who Really Cares?" in Technology Standards and Standardization Processes: Their Impact on Innovation and International Competitiveness, pp.3-16, Stanford University Press, 1999 (see also <http://fuji.stanford.edu/seminars/fall98/sep24-p/sld001.html>).

[3] T. L. Friedman, The Lexus and the Olive Tree, Anchor Books, New York, 2000.

[4] Desi Rhoden, "Real-Time On-Line Standards, the Ever Changing JEDEC, and other Standard Topics," in Technology Standards \& Standardization Processes. Their Impact on Innovation \& International Competitiveness, pp.32 -41, Stanford University Press, 1999 (see also $<$ http://fuji.stanford.edu/seminars/fall98/oct8-p.pdf >).

[5] Transatlantic Business Dialogue <http://www.tabd.com>.

[6] National Standards Strategy for the United States, The American National Standards Institute, 2000 $<$ http://web.ansi.org/public/nss.html>.

[7] Andrew Updegrove, "Forming and Representing High-Technology Consortia: Legal and Strategic Issues," The Computer Lawyer, March 1994 <http://www.lgu.com/pubs/cons47.htm>.

[8] John Browning and Spencer Reiss, "The Encyclopedia of the New Economy," Wired, Aug. 1998 <http://hotwired.lycos.com/special/ene>.

[9] Geoffrey Moore, "Standards and the Gorilla Game: The Dynamics of Setting Standards in High-Tech Markets" in Technology Standards and Standardization Processes: Their Impact on Innovation and International Competitiveness. pp.117 - 134, Stanford University Press, 1999 (see also $<$ http://fuji.stanford.edu/seminars/fall98/dec3-p/sld001.html>).

[10] Carl Shapiro and Hal R. Varian, Information Rules. Harvard Business School Press, 1999.

[11] Sean P. Gates, "Standards, Innovation, and Antitrust: Integrating Innovation Concerns into the Analysis of Collaborative Standard Setting," Emory Law Journal, Volume 47, Number 2, Spring 1998 <http://www.law.emory.edu/ELJ/volumes/spg98/gates.html>.

[12] “Agreement on Technical Barriers to Trade," The World Trade Organization, $<$ http://www.wto.org/english/docs_e/legal_e/17-tbt.pdf>.

[13] National Technology Transfer and Advancement Act (Public Law 104-113), <http://ts.nist.gov/ts/htdocs/210/nttaa/113.htm>.

[14] Andrew Updegrove, "U.S. Government Initiative Boosts Standards,” The Technology Law Bulletin, July $1996<$ http://www.lgu.com/pubs/cons50.htm>.

[15] "Federal Participation in the Development and Use of Voluntary Consensus Standards and in Conformity Assessment Activities," Office of Management and Budget (OMB) Circular A-119, February 10, 1998 $<$ http://www.dsp.dla.mil/omba119.htm>. 
[16] "Memorandum of Understanding between the American National Standards Institute (ANSI) and the National Institute of Standards and Technology (NIST),"

<http://ts.nist.gov/ts/htdocs/210/nttaa/ansimou.htm>, December 2000.

[17] Carl F. Cargill, "The Role of Consortia Standards in Federal Government Procurements in the Information Technology Sector: Towards a Re-Definition of a Voluntary Consensus Standards Organization," testimony before the House Science Committee's Subcommittee on Technology, Environment, and Standards, June 27, 2001 <http://www.house.gov/science/ets/jun28/cargill.pdf>.

[18] <http://www.fcc.gov/Bureaus/Wireless/Orders/1999/fcc99085.txt>.

[19] "Annual budget for the CEN Management Centre (1999), European Committee for Standardization $<$ http://www.cenorm.be/aboutcen/whatis/corporate/budget.htm>.

[20] “Agreement On Technical Cooperation Between ISO and CEN (Vienna Agreement)," 1995 $<$ http://isotc.iso.ch/livelink/livelink/fetch/2000/2123/SDS_WEB/sds_dms/vienna.pdf>.

[21] “IEC - CENELEC Agreement on Common Planning of New Work and Parallel Voting," European Committee for Electrotechnical Standardization, $1996<$ http://www.iec.ch/cenelec.htm>.

[22] "Market-Driven Consortia: Implications For The FCC's Cable Access Proceeding” (Working Draft), The Center for Regulatory Effectiveness, July 20, $2000<\mathrm{http}$ //www.thecre.com/action/whitepaper.html>.

[23] Roger B. Marks, "Broadband Wireless Access for the First Mile," National Science Foundation "Last Mile Panel," April 8, 1999 <http://nwest.nist.gov/first_mile.pdf>.

[24] Roger B. Marks, "Standards Make Wireless Work," Applied Microwave \& Wireless Magazine, pp. 101102, February $1999<\mathrm{http}: / /$ nwest.nist.gov/editorial_amw.html>.

[25] Roger B. Marks, “Cooperative International Wireless Standardization,” European Institute Roundtable: Spanning the Spectrum of Communications Policy, May 6, 1999

<http://www.standardsresearch.org/standards-discuss/0006.html>.

[26] Roger B. Marks, "IEEE Standardization for the Wireless Engineer," IEEE Microwave Magazine, pp. 1626, June $2001<$ http://WirelessMAN.org/docs/01/80216c-01_09.pdf>.

[27] Roger B. Marks, Ian C. Gifford, and Bob O'Hara, "Standards from IEEE 802 Unleash the Wireless Internet," IEEE Microwave Magazine, pp. 46-46, June 2001 <http://WirelessMAN.org/docs/01/80216c01_10.pdf>.

[28] Roger B. Marks, “The National Wireless Electronic Systems Testbed: Initial Development,” MTT-S European Topical Congress on Technologies for Wireless Applications, Amsterdam, pp. 220-223, October 7-9, $1998<$ http://nwest.nist.gov/eumc.html>.

[29] Submission of Testimony for the Record by Raymond G. Kammer, Director, National Institute of Standards and Technology, before the House Science Committee's Subcommittee on Technology (Standardization of Wireless Internet Technologies), April 11, 2000

$<$ http://www.nist.gov/testimony/2000/wireless.htm>.

\footnotetext{
About the Authors

Roger B. Marks<marks@nist.gov> is a physicist with the National Institute of Standards and Technology (NIST). $\mathrm{He}$ is the originating and current Chair of the IEEE 802.16 Working Group on Broadband Wireless Access Standards <http://WirelessMAN.org>. Marks received his Ph.D. in applied physics from Yale University in 1988. Robert E. Hebner <r.hebner@mail.utexas.edu> is Director of the Center for Electromechanics at The University of Texas at Austin. He received his Ph.D. in physics from the University of Missouri in 1971. He subsequently served many years with NIST, directing the agency from 1997 to 1999 and supporting initial development of NIST's strategy in broadband wireless access standards. Both Dr. Marks and Dr. Hebner are Fellows of the IEEE.
} 